\title{
The Effect of Initial Annealing Microstructures on the Forming Characteristics of Ti-4Al-2V Titanium Alloy
}

\author{
Bin Yan, Hongbo Li *, Jie Zhang and Ning Kong
}

School of Mechanical Engineering, University of Science and Technology Beijing, Beijing 100083, China; yanb_1988@163.com (B.Y.); zhangjie@ustb.edu.cn (J.Z.); kongning@ustb.edu.cn (N.K.)

* Correspondence: lihongbo@ustb.edu.cn; Tel.: +86-10-62333176

Received: 6 May 2019; Accepted: 16 May 2019; Published: 17 May 2019

\begin{abstract}
In this study, the effect of initial annealing microstructure of Ti-4Al-2V (TA17) alloy on forming characteristic was studied, so as to provide a basis for quality control of plastic forming of titanium alloy parts. The titanium alloy always undergoes annealing treatment before forming, due to different microstructures present different mechanical properties. The TA17 with different microstructures are obtained by means of various annealing treatment temperatures. The tensile behavior of TA17 is investigated at room temperature and $900{ }^{\circ} \mathrm{C}$ under constant strain rate of $0.01 \mathrm{~s}^{-1}$. The experimental results show that the mechanical properties of TA17 are sensitive to the initial microstructure before deformation. The microstructure of TA17 at $850{ }^{\circ} \mathrm{C}(2 \mathrm{~h})$ is the equiaxed primary $\alpha$-phase after the annealing process. It exhibits good plasticity at room temperature. This phenomenon is also confirmed from fracture morphology from the scanning electron microscope (SEM) analysis. At $900{ }^{\circ} \mathrm{C}$, which is a high tensile temperature, the alloy with equiaxed primary $\alpha$-phase performs outstanding plasticity compared with other microstructures. This work establishes a good understanding on the relationship between the mechanical properties and microstructures of TA17 at a wide temperature range.
\end{abstract}

Keywords: heat treatment; fractograph; hot-mechanical properties; microstructure; titanium alloys

\section{Introduction}

Titanium has been widely applied in an amount of areas including transportation, automotive industries [1], petrochemical, and marine [2]. It is also popular in the aerospace field [3], including gas turbine engines, load-carrying airframes, and wallboards because of its high strength-to-weight ratio, good toughness, resistance to corrosion, excellent thermal stability, and strength [4,5]. The Ti-4Al-2V (TA17) is of near $\alpha$ titanium alloy which is widely applied for aerospace applications and the high-pressure water/steam and high-temperature environment [6]. Titanium alloy is usually deformed at high temperature, such as $900{ }^{\circ} \mathrm{C}$, in order to avoid low ductility and spring back. The mechanical properties of titanium alloys are closely dependent on the microstructure, such as volume fraction, morphology, and grain size of $\alpha$ and $\beta$ phases $[7,8]$. Furthermore, flow instability is caused by flow softening, which may result in deformation defects. The flow softening behavior is significantly affected by the initial microstructure when deforming under the $\beta$ transus temperature [9]. The deformation is able to change the microstructure of alloys. The forming quality is greatly influenced by the mechanical properties. Titanium alloy usually undergoes annealing treatments to get the appropriate microstructure and mechanical properties. Therefore, studying the effect of the initial microstructure on mechanical properties is necessary for the application of titanium alloy during the forming process.

Many studies reported about the mechanical properties and microstructures of titanium alloys, which provide important guidance for the application of titanium alloy. Guo et al. [10] have studied the direct relationship between the mechanical properties and the microstructure of TC4-DT titanium alloy. 
The result showed that the microstructure feature could be altered by heat-treatment. The cooling speed and aging conditions present a significant influence on the microstructure. Zhao et al. [11] have studied on the mechanical properties, microstructures, and fractographs of TA15 titanium alloys vacuum-annealed under different patterns. Their work show that different annealing temperatures affect the grain boundaries and the volume fraction of secondary $\alpha$-phase. The content of primary $\alpha$-phase decreases with the increasing annealing temperature, which lead to the increased strength and decreased elongation. Luo et al. [12] also came to a conclusion that the initial microstructure plays a key role on the strain hardening exponent of the Ti-5Al-2Sn-2Zr-4Mo-4Cr titanium alloy. The effect of strain and strain rate is related to the initial microstructure. Peng et al. [13] studied the relationship between mechanical properties and microstructures of TC4-DT alloy which obtained from $\beta$ processing and $\beta$ treatment. The microstructures present a great influence on the fracture toughness, tensile strength, and plasticity. Cai et al. [14] studied the workability of Ti-6Al-4V titanium alloy by hot temperature compression tests. The Q-value (the activation energy of hot deformation) of $\alpha$ - $\beta$ phase is greatly higher than that of only $\beta$ phase region. Grain refinement is an effective approach to enhance the mechanical properties of metals and alloys [15,16]. Zhang et al. [17] investigated the influence of three different microstructures on the plastic flow behavior of Ti-6Al-4V. The $\alpha^{\prime}$ martensitic initial microstructure is more beneficial for achieving grain refinement.

From what has been described above, titanium alloy usually undergoes annealing treatments to obtain the desired microstructure and mechanical properties. Studying the effect of the initial microstructure on high temperature mechanical properties is necessary. Some studies have focused on the relationship between mechanical properties and initial microstructure of titanium alloy, but more systematic and comprehensive work needs to be done on TA17. Titanium alloy is generally deformed at hot temperatures [18]. However, the titanium alloy also can be deformed at room temperature when the deformation is small [19]. In the present work, different initial microstructures are obtained by different annealing treatments. The tensile tests were conducted with different initial microstructures of TA17 at room temperature and $900{ }^{\circ} \mathrm{C}$, respectively. The relationship is studied between the different initial microstructures and mechanical properties of TA17. Understanding the relationship between the initial microstructure, machining process, and fracture behavior of TA17 is particularly important to further improve the performance and reliability of the material and to provide some support for the optimization of the microstructure of TA17. Finally, the results will provide a basis for quality control of plastic forming of titanium alloy parts and a helpful basis for successful application in the superplastic forming technology.

\section{Material and Experimental Procedures}

\subsection{Materials}

A commercial TA17 sheet was used with the thickness of $2.0 \mathrm{~mm}$ in this work. The main compositions of TA17 is shown in Table 1 . The $\beta$-transus temperature of TA17 was determined via a series of heat treatments at $910 \sim 920^{\circ} \mathrm{C}$.

Table 1. Main chemical compositions of Ti-4Al-2V (TA17). (wt. \%).

\begin{tabular}{ccccccccc}
\hline $\mathbf{A l}$ & $\mathbf{V}$ & $\mathbf{F e}$ & $\mathbf{S i}$ & $\mathbf{O}$ & $\mathbf{N}$ & $\mathbf{H}$ & $\mathbf{C}$ & $\mathbf{T i}$ \\
\hline 4.3 & 2.1 & 0.25 & 0.15 & 0.15 & 0.05 & 0.015 & 0.08 & $\mathrm{Bal}$ \\
\hline
\end{tabular}

\subsection{Experimental Procedures}

Five experiments were conducted according to the annealing treatment processes commonly used in the actual production field, in order to obtain different initial microstructures. The processes of annealing treatment are shown in Table 2. The sample with epoxy resin shown in Figure 1a was grinded on increasing grit sizes abrasive papers until the scratches are not visible to the naked eye and then polished on diamond polishing powder. Subsequently, etching was performed by $10 \% \mathrm{HF}+15 \%$ 
$\mathrm{HNO}_{3}+75 \% \mathrm{H}_{2} \mathrm{O}$ solution for $10 \mathrm{~s}$, so as to obtain the microstructures. SEM was performed by using the SUPRA 55 (Zeiss, Germany), for analyses phases parameters, grain size and fracture morphology. The annealing treatments should carry out in a vacuum annealing environment. Titanium alloy is easy to react with $\mathrm{O}, \mathrm{N}$ and $\mathrm{H}$ in atmosphere, because of the high chemical activity. When the annealing temperature is over $750{ }^{\circ} \mathrm{C}$, the oxygen in the dense oxide layer will permeate into the titanium matrix. The oxide film breaks down and an oxidation layer can be formed between the oxide layer and the titanium alloy matrix. Figure $1 \mathrm{c}$ is the microstructure of TA17 which was annealed at $800{ }^{\circ} \mathrm{C}$ in a muffle furnace (Shanghai suoyu, Shanghai, China) and preserved for $2 \mathrm{~h}$ in the air condition. It shows the dense oxide layer has penetrated into the titanium matrix. Therefore, the annealing treatment experiment of TA17 plate was carried out under vacuum condition, in order to avoid oxidation. The annealing treatments were conducted in a Muffle furnace. Specimens sealed in quartz glass tubes with argon gas before annealing treatment, as shown in Figure 2a.

Table 2. The designed annealing process for TA17 sheets.

\begin{tabular}{cc}
\hline Annealing No. & Annealing Processes \\
\hline S1 & as received \\
S2 & $800{ }^{\circ} \mathrm{C} / 2 \mathrm{~h} / \mathrm{AC}$ (air cooling) \\
S3 & $850^{\circ} \mathrm{C} / 2 \mathrm{~h} / \mathrm{AC}$ \\
S4 & $900^{\circ} \mathrm{C} / 2 \mathrm{~h} / \mathrm{AC}$ \\
S5 & $950{ }^{\circ} \mathrm{C} / 2 \mathrm{~h} / \mathrm{AC}$ \\
S6 & $\left(950{ }^{\circ} \mathrm{C} / 2 \mathrm{~h} / \mathrm{AC}\right)+\left(600^{\circ} \mathrm{C} / 2 \mathrm{~h} / \mathrm{AC}\right)$ \\
\hline
\end{tabular}
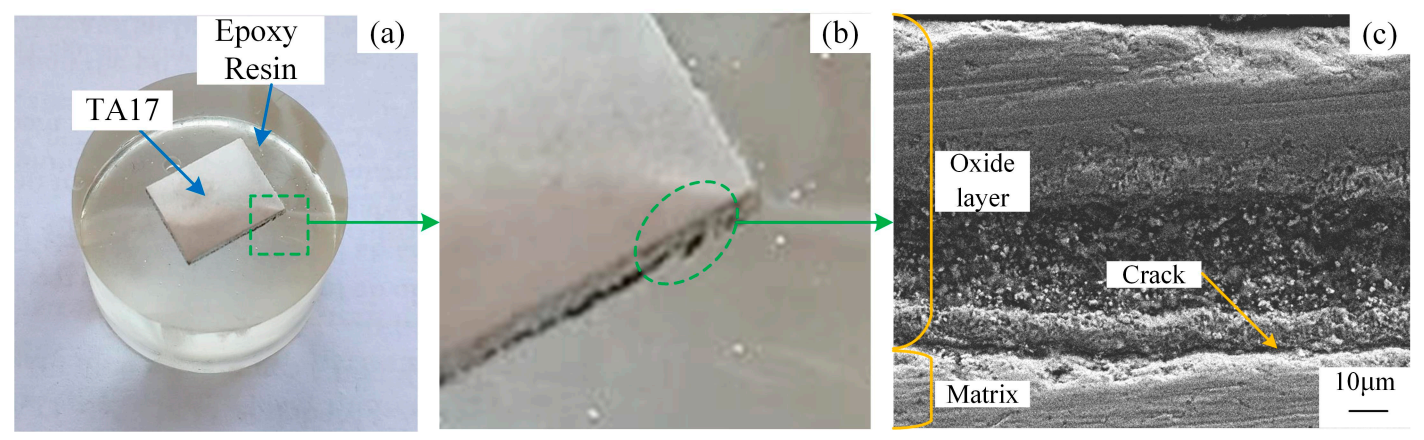

Figure 1. (a) Specimen for scanning electron microscope (SEM); (b) The partial enlarged view; (c) The microstructure of TA17 after $800^{\circ} \mathrm{C}$ oxidation.

(a)
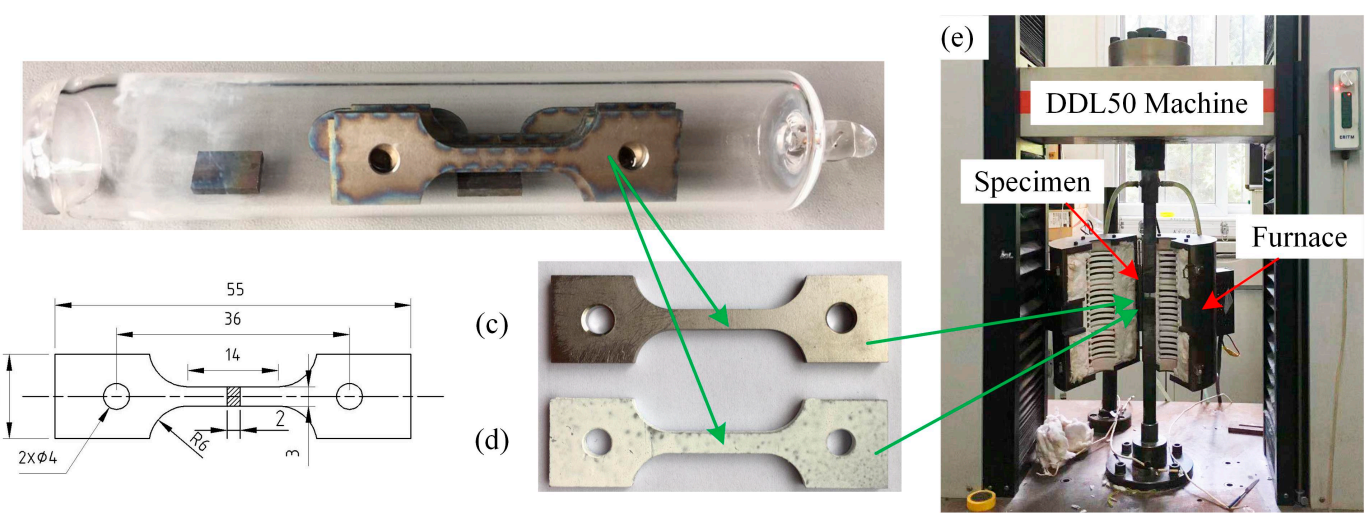

Figure 2. (a) Specimens in quartz glass tubes; (b) Diagram of specimen used in tensile tests (Unit: $\mathrm{mm}$ ); (c) Specimen without antioxidant; (d) Specimen with antioxidant; (e) DDL50 electronic testing machine.

The Specimens were fabricated by laser cutting, as shown in Figure 2. The initial microstructures were obtained by annealing treatments. Then, the room and high temperature tensile experiments 
were conducted on DDL50 testing machine (Changchun mechanical research institute, Changchun, China), shown in Figure 2e. The high temperature tensile tests were conducted with a steady strain rates of $0.01 \mathrm{~s}^{-1}$ and tensile testing temperature of $900{ }^{\circ} \mathrm{C}$ which are commonly used in industrial forming production. Before the high temperature tests, the surface of tensile specimens was spread over a thin special antioxidant so as to protect the specimen from early failure and damage caused by oxidation during deformation, as shown in Figure $2 \mathrm{~d}$. Then the specimens were annealed to the desired deformation temperature in a furnace with temperature error less than $4{ }^{\circ} \mathrm{C}$. The specimens were held for $5 \mathrm{~min}$ at the target temperature before tension. Each experiment was repeated three times. The average values of three tested results were obtained, in order to reduce the error. The test results of displacement and force data were translated into the true stress-strain parameters by using Equations (1) and (2).

$$
\begin{gathered}
\varepsilon=\ln \frac{l}{l_{0}}=\ln \left(\frac{l_{0}+\Delta l}{l_{0}}\right), \\
\sigma=\frac{F}{A}=\frac{F l}{A_{0} l_{0}}=\frac{F\left(l_{0}+\Delta l\right)}{A_{0} l_{0}}=\frac{F}{A_{0}}\left(l+\frac{\Delta l}{l_{0}}\right),
\end{gathered}
$$

where $F$ is the transient load, $l_{0}$ is the gauge length, $A_{0}$ is the initial cross-sectional area, $A$ is the transient cross-sectional area, $l$ is the transient gauge length, $\Delta l$ is the transient extension gauge length, $\sigma$ is the true stress and $\varepsilon$ is the true strain.

\section{Results and Discussion}

\subsection{Different Microstructures}

Different microstructures were obtained by different annealing treatments. The microstructure of TA17 without annealing is exhibited in Figure 3a. The original microstructure is made up mainly by the equiaxed primary $\alpha$-phase [10,11] (dark) and a little of intergranular $\beta$ (bright). The grain size of $\alpha$-phase is about $14 \mu \mathrm{m}$. The initial volume fraction of the $\beta$-phase is about $4.3 \%$ as measured by Image-Pro Plus 6.0 (Media Cybernetics, Rockille, MD, USA). The microstructure is not changed obviously after annealing treatments of $800^{\circ} \mathrm{C}$ and $850^{\circ} \mathrm{C}$, as shown in Figure $3 \mathrm{~b}$,c. However, the size of the equiaxed $\alpha$-phase turns finer when the annealing temperature is $850^{\circ} \mathrm{C}$. It provides evidence that the grain can be refined by the $\alpha-\beta$ solution treatment [20]. At an annealing temperature of $900{ }^{\circ} \mathrm{C}$, some Widmanstätten $[10,11]$ appears in the equiaxed $\alpha$-phase (Figure $3 \mathrm{~d}$ ). The microstructure is all Widmanstätten at the annealing temperature of $950^{\circ} \mathrm{C}$, as shown in Figure 3e. In Figure 3f, the microstructures changes from Widmanstätten structure to bimodal structure after the annealing of $\left(\left(950^{\circ} \mathrm{C} / 2 \mathrm{~h} / \mathrm{AC}\right)+\left(600{ }^{\circ} \mathrm{C} / 2 \mathrm{~h} / \mathrm{AC}\right)\right)$. The obtained microstructures will be used in subsequent tensile tests.

\subsection{The Room Temperature Mechanical Properties}

\subsubsection{Mechanical Properties}

Tensile tests were conducted to obtain the tensile properties of TA17 at room temperature. The specimens after different annealing treatments at Section 3.1 were used. The strength and elongation are very different with different initial microstructures at room temperature. The mechanical properties of TA17 are sensitive to the microstructures at room temperature, as shown in Table 3 and Figure 4. 
Table 3. The room temperature mechanical properties of TA17 with different microstructures.

\begin{tabular}{cccc}
\hline Annealing No. & Yield Strength $\mathbf{( M P a )}$ & Peak Strength (MPa) & Elongation (\%) \\
\hline S1 & 745.3 & 821.3 & 16.7 \\
S2 & 734.1 & 824.2 & 18.7 \\
S3 & 814.8 & 911.8 & 20.8 \\
S4 & 739.2 & 822.9 & 15.9 \\
S5 & 812.5 & 886.7 & 10.5 \\
S6 & 793.7 & 854.6 & 11.9 \\
\hline
\end{tabular}
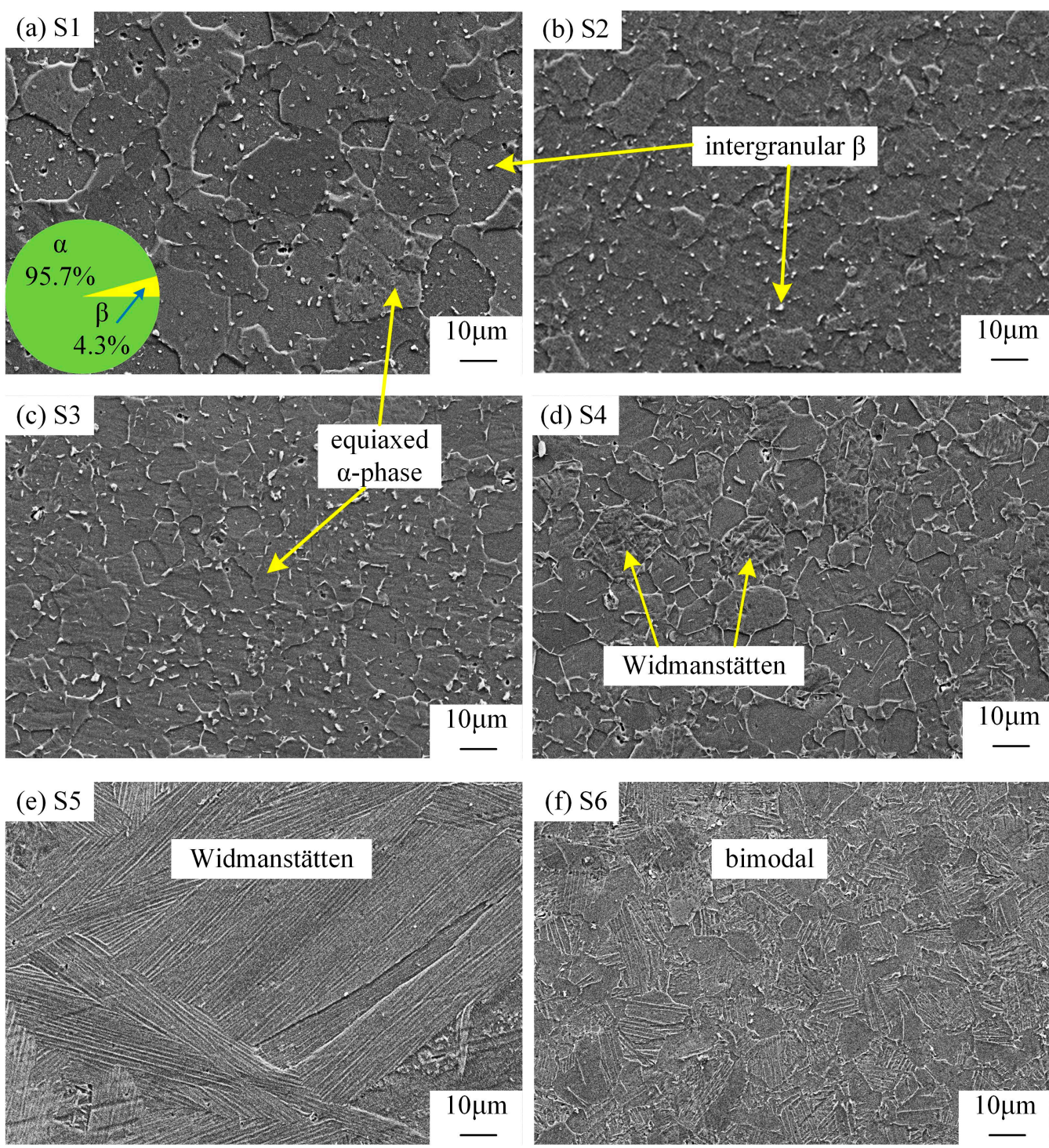

Figure 3. The microstructures of TA17 after different annealing processes. (a) S1; (b) S2; (c) S3; (d) S4; (e) S5; and (f) S6. 

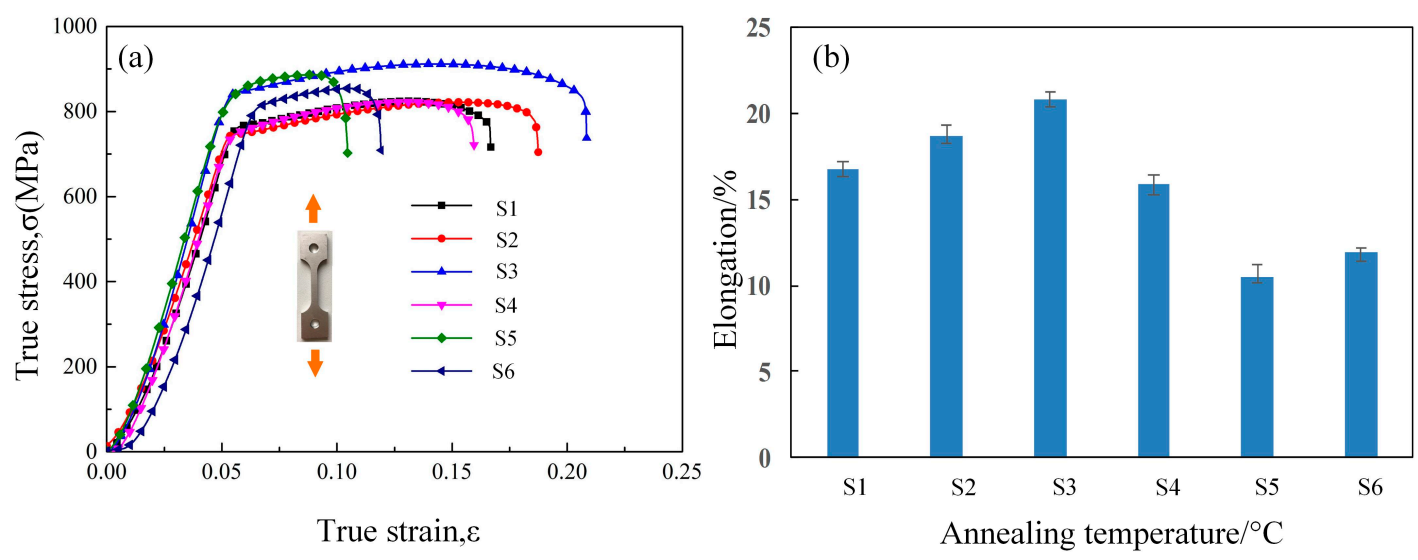

Figure 4. The tensile properties at room temperature (a) and elongation (b) with different initial microstructures.

As the annealing temperature rises, the plasticity increases at first, then decreases after $850{ }^{\circ} \mathrm{C}$. The Widmanstätten structure obtained from annealing at $950{ }^{\circ} \mathrm{C}$ presents the minimum plasticity. However, the plasticity is improved under the annealing condition of $\left(\left(950^{\circ} \mathrm{C} / 2 \mathrm{~h} / \mathrm{AC}\right)+\left(600{ }^{\circ} \mathrm{C} / 2 \mathrm{~h} / \mathrm{AC}\right)\right)$, compared to $\left(950^{\circ} \mathrm{C} / 2 \mathrm{~h} / \mathrm{AC}\right)$. It is found that outstanding mechanical properties are obtained after the annealing of $\left(850^{\circ} \mathrm{C} / 2 \mathrm{~h} / \mathrm{AC}\right)$, the yield strength, peak strength, and fracture elongation of the TA17 are $834.4 \mathrm{MPa}, 911.9 \mathrm{Mpa}$, and $20.8 \%$, respectively. At $850{ }^{\circ} \mathrm{C}$, the finer equiaxed microstructure appears. Fine equiaxed $\alpha$ grain improves the appropriate deformation among the microstructure parameters, and causes crossing slip of slip systems [7]. Comparing to the original sheets of TA17, the elongation can be increased by the annealing at $850{ }^{\circ} \mathrm{C} / 2 \mathrm{~h} / \mathrm{AC}$. The tensile deformation of equiaxed and Widmanstätten structure began with slipping among the individual grains of primary $\alpha$-phase $\left(\alpha_{\mathrm{p}}\right)$. With the increasing deformation, the slip occupies more and more $\alpha$ grains and extends in the transformed $\beta$ microstructure $\left(\beta_{t}\right)$ boundaries. The lamellar structure of $\beta_{t}$ in different layers shows the same habit plane. The dislocations quickly pass through the parallel $\alpha$ layers, which may lead to slip bands and the uneven deformation of micro areas, as well as the formation and development of holes. Finally, the sample broke prematurely. The volume fraction of $\alpha_{p}$ affects the spacings of the slip bands and the uniformity of the microregion plastic deformation, so as to affect the plasticity deformation. The more the volume fraction of $\alpha_{\mathrm{p}}$, the greater the slip degree, which contributes to a higher plasticity value [21].

\subsubsection{Fractograph Analysis}

Figure 5 has the fractographs of the vacuum-annealed specimens after tensile tests at room temperature. It shows obvious ductile fracture with plentiful dimples. Within a temperature range of $800 \sim 850{ }^{\circ} \mathrm{C}$, the dimples become much deeper and bigger (Figure $5 \mathrm{c}-\mathrm{e}$ ) with increasing the annealing temperature. This is caused by recovery and recrystallization, which produces much more slipping systems, which caused the plasticity of TA17 to rise. The deepest and biggest dimples with almost no facets are discovered in the specimens annealing at $850{ }^{\circ} \mathrm{C}$, which is responsible to the outstanding plasticity of TA17 [21]. 

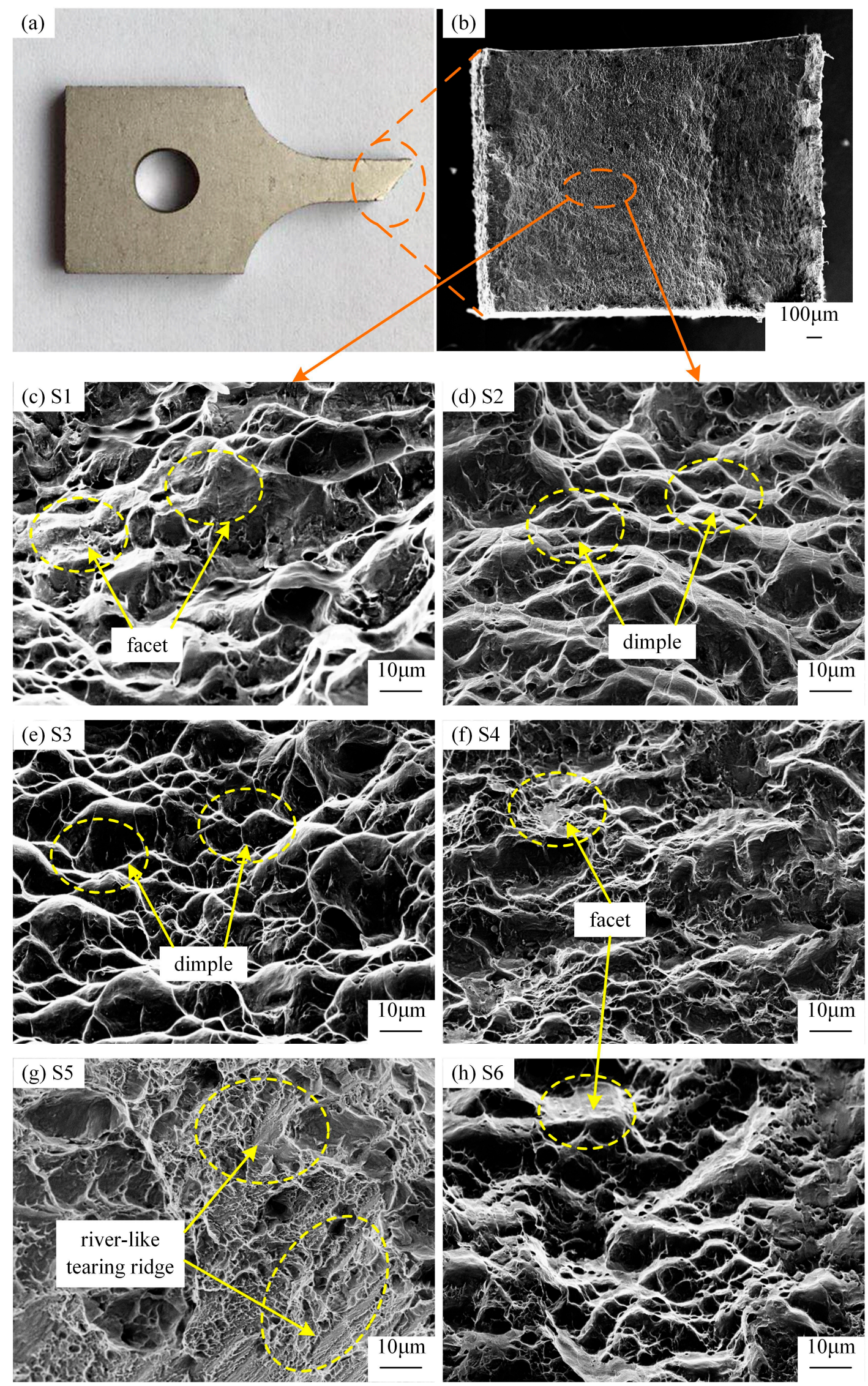

Figure 5. The tensile fracture surface morphology under different annealing processes. (a) The fracture sample; (b) Fracture profile; (c) S1; (d) S2; (e) S3; (f) S4; (g) S5; and (h) S6. 
If the annealing temperature is higher than $850^{\circ} \mathrm{C}$, a large number of facets appear among the dimples and the dimples become shallow (Figure $5 f, g$ ), $\alpha_{s}$ begins to precipitate from the $\beta$-phase due to the content of $\alpha_{\mathrm{p}}$ decreases [11]. There are much phase boundaries to hinder slipping. Therefore, the deformation of the alloy becomes more difficult. In Figure 5f, the shape and size of dimples are irregular. Figure $5 \mathrm{~g}$ shows evident river-like tearing ridges with almost no dimples. This phenomenon shows that TA17 exhibits the lowest plasticity after annealing at $950{ }^{\circ} \mathrm{C}$.

The dimples appear again after the annealing of $\left(\left(950^{\circ} \mathrm{C} / 2 \mathrm{~h} / \mathrm{AC}\right)+\left(600^{\circ} \mathrm{C} / 2 \mathrm{~h} / \mathrm{AC}\right)\right)$, as shown in Figure $5 \mathrm{~h}$. But the dimples are shallow and small. This indicates that double annealing alters tissue morphology and improves plasticity on a limited extent. The fractographs results are in accordance with the plasticity trend of the TA17 exhibited in Figure 4.

\subsection{The Hot-Mechanical Properties of Different Microstructures}

It was investigated in actual production that the forming temperature and strain rate of TA17 titanium alloy usually are $900{ }^{\circ} \mathrm{C}$ and $0.01 \mathrm{~s}^{-1}$, respectively. The specimens after different annealing treatments at Section 3.1 were used. For studying the influence of initial microstructure on the flow behavior, the high temperature tensile tests were conducted with the TA17 which are conducted by five different annealing treatments. The $900^{\circ} \mathrm{C}$ mechanical properties of TA17 with different microstructures are shown in Table 4. Flow curves from tensile tests are summarized in Figure 6a. It can be found that the tendency of these curves is similar with different initial microstructures. The curves usually consist of four different parts, including: (1) elastic part, (2) uniform deformation part, (3) diffusion necking part, and (4) localized necking part, shown in Figure $6 b[22,23]$. These curves appear to have an early yield drop. The reason is that there is little time for recovery process due to high strain rates, and dislocation pile-up results in higher local stress concentrations. Therefore, enough high applied stress must be applied to release dislocations from their fixing points. And the flow stress quickly rises to the peak stress after yielding. Subsequently, the curve declines with further deformation until the specimen is broken.

Table 4. The $900{ }^{\circ} \mathrm{C}$ mechanical properties of TA17 with different microstructures.

\begin{tabular}{cccc}
\hline Annealing No. & Yield Strength (MPa) & Peak Strength (MPa) & Elongation (\%) \\
\hline S1 & 59.1 & 63.9 & 90.5 \\
S2 & 68.4 & 72.5 & 94.8 \\
S3 & 60.5 & 65.8 & 127.3 \\
S4 & 72.1 & 76.0 & 73.1 \\
S5 & 103.3 & 107.1 & 52.0 \\
S6 & 72.6 & 77.5 & 48 \\
\hline
\end{tabular}

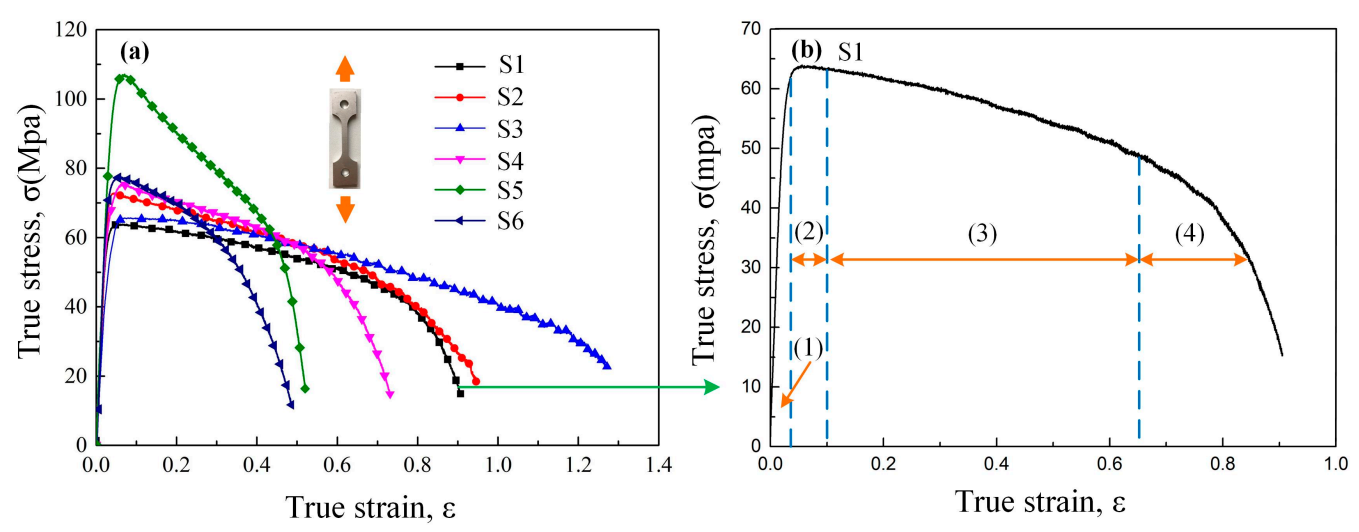

Figure 6. (a) The $900^{\circ} \mathrm{C}$ flow curves of TA17 with different microstructures. (b) Four parts of the typical true $\sigma-\varepsilon$ curve. 
With temperature increasing, the critical stress to start dislocation decreased. The peak stress at room temperature was higher than the corresponding ones measured at $900{ }^{\circ} \mathrm{C}$. The slip of grain or phase boundary happens easier when the deformation temperature increases [24,25]. The peak stress of the titanium alloy is seriously influenced by the initial microstructure. As shown in Figure 6a, the specimen with the Widmanstätten obtains the highest peak stress of $107.1 \mathrm{Mpa}$. The $\alpha / \beta$ interfaces hinder the dislocations and an abundance of dislocations are focused near the phase boundaries in the Widmanstätten. More boundaries cause greater resistance for dislocations' motion [7]. This is why the alloy with the initial microstructures of Widmanstätten got the highest strength. Widmanstätten also presents the greatest creep resistance, which reduces the grain boundary sliding [26].

\subsection{The Superplasticity of TA17}

The deformation of the equiaxed primary $\alpha$-phase which obtained after annealing at $850{ }^{\circ} \mathrm{C}$ is $127.3 \%$, which exhibits best plasticity. Its initial microstructure is equiaxed primary $\alpha$-phase. The grains of equiaxed primary $\alpha$-phase are the finest. The strain rate sensitivity exponent $(m)$ is the significant parameter to show the ability of plastic deformation. It is applied to evaluate the deformation mechanisms of materials [27]. The $m$-value is computed by the Equation (3) [28]. The material exhibits superplasticity when $m$ is greater than 0.3 [29].

$$
m=\left.\frac{d \log \sigma}{d \log \dot{\varepsilon}}\right|_{\varepsilon, T},
$$

where $\sigma$ is the true stress (MPa), $\dot{\varepsilon}$ is the strain rate $\left(\mathrm{s}^{-1}\right), \varepsilon$ is the true strain, and $T$ is the absolute deformation temperature $(\mathrm{K})$.

The $900{ }^{\circ} \mathrm{C}$ tensile tests were conducted using TA17 after annealing at $850{ }^{\circ} \mathrm{C}$, in order to obtain the $m$-value. The flow behavior of TA17 with the different strain rates are shown in Figure 7a. From Figure $7 \mathrm{~b}$, the $m$-value can be computed by the slope of $\ln \sigma$-ln $\dot{\varepsilon}$ curve. The linear relationship between $\ln \sigma$ and $\ln \dot{\varepsilon}$ is fine. The slope of $\ln \sigma-\ln \dot{\varepsilon}$ is about 0.33 by using linear fitting. It means the $m$-value is 0.33 . The true stress decreased rapidly after it rising to the peak. Then it was smooth before the fracture. The TA17 after annealing at $850{ }^{\circ} \mathrm{C}$ exhibited superplasticity which is beneficial to plastic forming in industrial production. The $m$-values of the fine-grained material is larger than the coarse-grained one. The fine-grained titanium alloy is more prone to happen the grain boundary slip comparing with the coarse-grained titanium alloy [30]. The initial microstructure of bimodal structure exhibits the lowest plasticity with 0.49 .

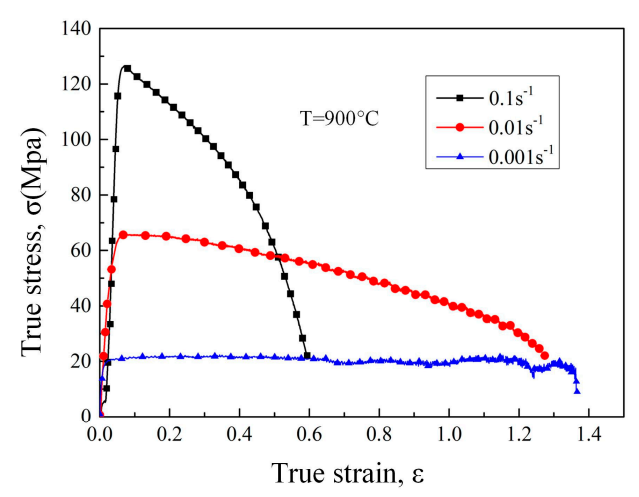

(a)

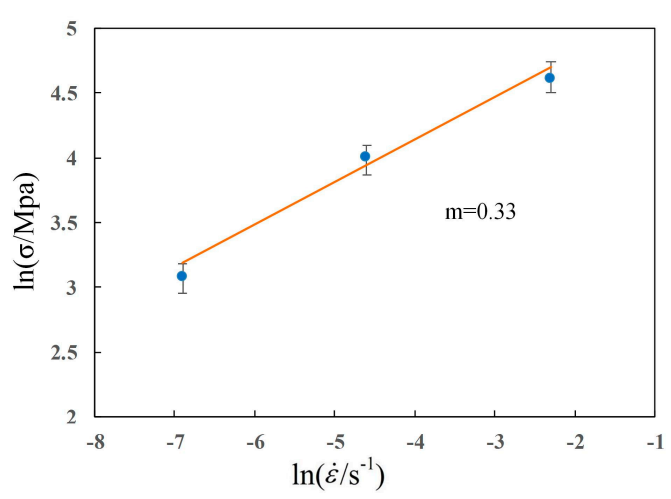

(b)

Figure 7. (a) The flow curves of TA17 with different strain rates at $900{ }^{\circ} \mathrm{C}$. (b) The $m$-value.

The high temperature plasticity is influenced by the secondary $\alpha$-phase $\left(\alpha_{s}\right)$. The deformation of $\beta_{\mathrm{t}}$ firstly appears in $\beta$-phase and gradually diffuses to $\alpha_{\mathrm{s}}$. The $\alpha / \beta$ boundaries manifest a near-Burgers orientation relationship which are $(0001)_{\alpha} / /(101)_{\beta}$ and $[2 \overline{1} \overline{1} 0]_{\alpha} / /[\overline{1} \overline{1} \overline{1}]_{\beta}$. When dislocations slip along 
the slipping system of $(101)_{\beta}[\overline{1} \overline{1} \overline{1}]_{\beta}$ in the $\beta$-phase, they can easily cross the $\alpha / \beta$ boundaries $[7,23]$. The deformation can extend from the $\beta$ phase to the $\alpha_{\mathrm{s}}$. Plastic deformation is much easier obtained in a primary $\alpha$-phase than in a lamellar structure, because there is a small spacing among the slip zone of equiaxed tissue. As the annealing temperature increases, the content of $\beta_{t}$ increases, which results in the elongation of the sheets decreasing [11]. Therefore, the elongation firstly increases and then decreases with the annealing temperature increasing.

As for the mechanisms of superplastic deformation, good elongation is mainly caused by grain boundary slip. The dispute about the regulative mechanisms on the grain boundary slip are never ended. Several theories have been proposed to explain material flow at high temperature [30]. Many scholars have also studied on the superplastic deformation behavior of titanium alloys which shows relation between temperature and strain rate [31]. In this study, the superplastic property depends on the initial microstructure.

The obtained results indicate that the different initial microstructures exhibit different hot-mechanical properties. The plasticity of TA17 can be significantly enhanced by annealing treatments. The overall mechanical mechanism is shown in Figure 8.

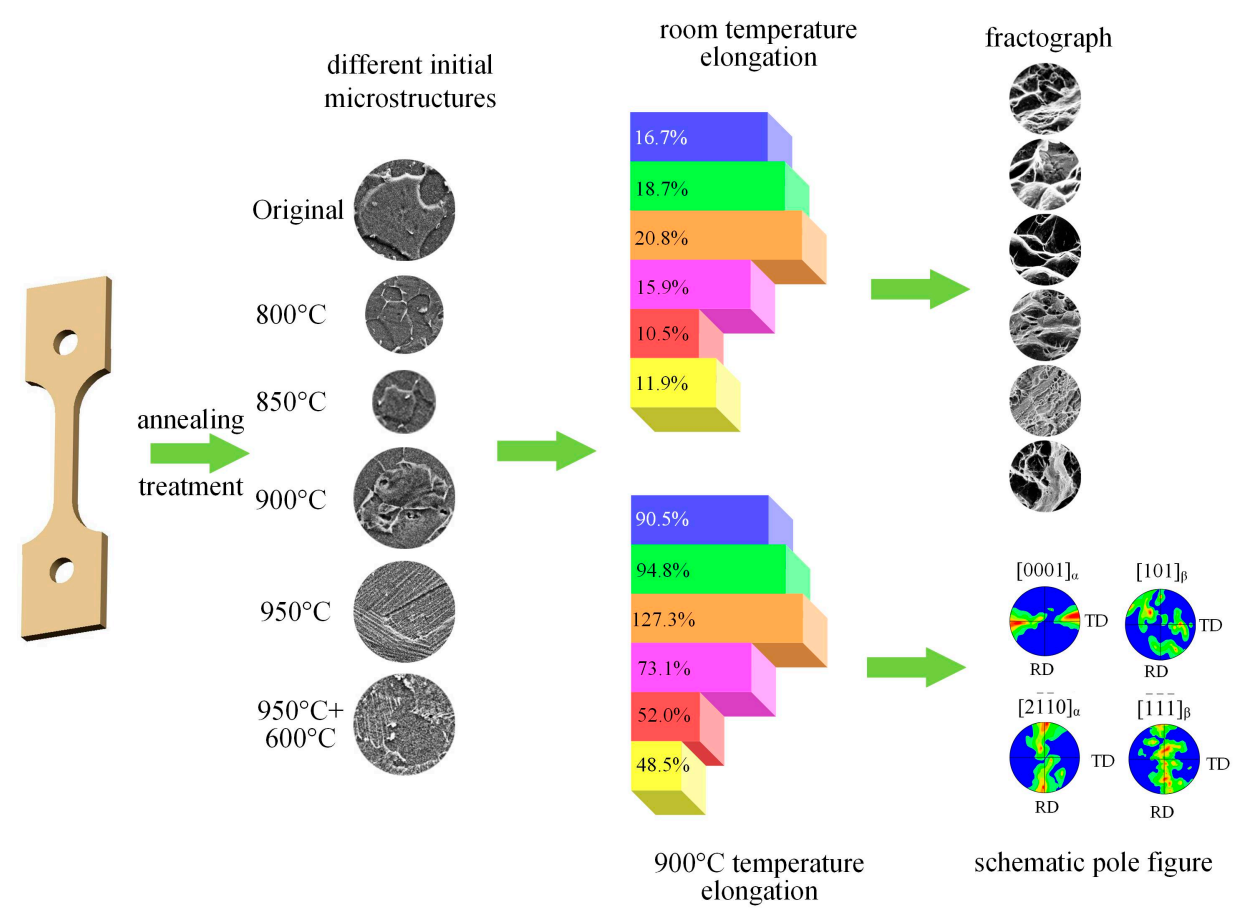

Figure 8. Schematic diagram of mechanical mechanism.

\section{Conclusions}

In this work, the commercial TA17 sheet had annealing treatments performed on it to obtain different initial microstructures. The tensile test was conducted at both room and high temperatures. The influence of initial microstructure on forming characteristic was studied. The conclusions of the current study are as follows:

(1) The room-mechanical properties of TA17 alloy are sensitive to initial microstructures. Annealing treatment could change the mechanical properties of the TA17. The comprehensive mechanical properties of the TA17 are enhanced after annealing of $850^{\circ} \mathrm{C} / 2 \mathrm{~h} / \mathrm{AC}$ comparing with these after other annealing processes, because a finer equiaxed primary $\alpha$-phase is obtained.

(2) The hot-temperature mechanical properties of TA17 are sensitive to initial microstructures. Under tension at $900{ }^{\circ} \mathrm{C}$ and $0.01 \mathrm{~s}^{-1}$, the TA17 with initial microstructure of Widmanstätten exhibits highest peak stress of 107.1 Mpa. The TA17 after annealing of $850{ }^{\circ} \mathrm{C} / 2 \mathrm{~h} / \mathrm{AC}$ exhibits the best plasticity of $127.3 \%$ and an $m$-value of 0.33 , which presents superplastic forming capability. 
Author Contributions: B.Y. performed the experiments and wrote the paper; H.L. and J.Z. conceived and designed the experiments; N.K. did the former analysis.

Funding: This work is supported by the Fundamental Research Funds for the Central Universities (No. FRF-GF-17-B22). Also, the work is supported by the National Key R\&D Program of China (No. 2016YFB0301204) and the National Natural Science Foundation of China (No. 51605026).

Conflicts of Interest: The authors declare no conflict of interest.

\section{References}

1. Yang, H.; Li, L.; Wang, Q.; Guo, L. Research on the Development of Advanced Forming for Lightweight Alloy Materials Area. J. Mech. Eng. 2010, 46, 31-32. [CrossRef]

2. Wu, J.; Lv, Z.D.; Zhang, C.J.; Han, J.C.; Zhang, H.Z.; Zhang, S.Z.; Hayat, M.; Cao, P. Investigation of the Deformation Mechanism of a near $\beta$ Titanium Alloy through Isothermal Compression. Metals 2017, 7, 498. [CrossRef]

3. Peters, M.; Kumpfert, J.; Ward, C.H.; Leyens, C. Titanium Alloys for Aerospace Applications. Adv. Eng. Mater. 2003, 5, 419-427. [CrossRef]

4. Li, J.L.; Wang, B.Y.; Huang, H.; Fang, S.; Chen, P.; Shen, J.X. Unified modelling of the flow behaviour and softening mechanism of a TC6 titanium alloy during hot deformation. J. Alloys Compd. 2018, 748, 1031-1043. [CrossRef]

5. Xiao, J.; Li, D.S.; Li, X.Q.; Deng, T.S. Constitutive modeling and microstructure change of Ti-6Al-4V during the hot tensile deformation. J. Alloys Compd. 2012, 541, 346-352. [CrossRef]

6. Huang, D.M.; Yang, X.F.; Wei, Q.F.; Chen, Y.; Guo, H.; Liang, S.L.; Wang, Y. Causes of surface stripe cracks of Ti-4Al-2V alloy cold-rolled sheet. Rare Met. 2014, 33, 522-526. [CrossRef]

7. Wang, T.; Guo, H.Z.; Wang, Y.W.; Peng, X.N.; Zhao, Y.; Yao, Z.K. The effect of microstructure on tensile properties, deformation mechanisms and fracture models of TG6 high temperature titanium alloy. Mater. Sci. Eng. A 2011, 528, 2370-2379. [CrossRef]

8. Velay, V.; Matsumoto, H.; Vidal, V.; Chiba, A. Behavior modeling and microstructural evolutions of Ti-6Al-4V alloy under hot forming conditions. Int. J. Mech. Sci. 2016, 108-109, 1-13. [CrossRef]

9. Fan, X.G.; Yang, H.; Gao, P.F. The mechanism of flow softening in subtransus hot working of two-phase titanium alloy with equiaxed structure. Chin. Sci. Bull. 2014, 59, 2859-2867. [CrossRef]

10. Guo, P.; Zhao, Y.Q.; Zeng, W.D.; Hong, Q. The effect of microstructure on the mechanical properties of TC4-DT titanium alloys. Mater. Sci. Eng. A 2013, 563, 106-111. [CrossRef]

11. Zhao, H.J.; Wang, B.Y.; Liu, G.; Yang, L.; Xiao, W.C. Effect of vacuum annealing on microstructure and mechanical properties of TA15 titanium alloy sheets. Trans. Nonferr. Met. Soc. China 2015, 25, 1881-1888. [CrossRef]

12. Luo, J.; Li, L.; Li, M.Q. Deformation behavior of Ti-5Al-2Sn-2Zr-4Mo-4Cr alloy with two initial microstructures during hot working. Trans. Nonferr. Met. Soc. Chin. 2016, 26, 414-422. [CrossRef]

13. Peng, X.N.; Guo, H.Z.; Wang, T.; Yao, Z.K. Effects of $\beta$ treatments on microstructures and mechanical properties of TC4-DT titanium alloy. Mater. Sci. Eng. A 2012, 533, 55-63. [CrossRef]

14. Cai, J.; Li, F.G.; Liu, T.Y.; Chen, B.; He, M. Constitutive equations for elevated temperature flow stress of Ti-6Al-4V alloy considering the effect of strain. Mater. Des. 2011, 32, 1144-1151. [CrossRef]

15. Oliveira, D.P.; Prokofiev, E.; Sanches, L.F.R.; Polyakova, V.; Valiev, R.Z.; Botta, W.J.; Junior, A.M.J.; Bolfarini, C. Surface chemical treatment of ultrafine-grained $\mathrm{Ti}-6 \mathrm{Al}-7 \mathrm{Nb}$ alloy processed by severe plastic deformation. J. Alloys Compd. 2015, 643, S241-S245. [CrossRef]

16. Yu, H.B.; Zhang, D.L.; Chen, Y.Y.; Cao, P.; Gabbitas, B. Synthesis of an ultrafine grained TiAl based alloy by subzero temperature milling and HIP, its microstructure and mechanical properties. J. Alloys Compd. 2009, 474, 105-112. [CrossRef]

17. Zhang, Z.X.; Qu, S.J.; Feng, A.H.; Shen, J.; Chen, D.L. Hot deformation behavior of Ti-6Al-4V alloy: Effect of initial microstructure. J. Alloys Compd. 2017, 718, 170-181. [CrossRef]

18. Ma, B.L.; Wu, X.D.; Li, X.J.; Wan, M.; Cai, Z.Y. Investigation on the hot formability of TA15 titanium alloy sheet. Mater. Des. 2016, 94, 9-16. [CrossRef]

19. Badr, O.M.; Rolfe, B.; Hodgson, P.; Weiss, M. Forming of high strength titanium sheet at room temperature. Mater. Des. 2015, 66, 618-626. [CrossRef] 
20. Shekhar, S.; Sarkar, R.; Kar, S.K.; Bhattacharjee, A. Effect of solution treatment and aging on microstructure and tensile properties of high strength $\beta$ titanium alloy, Ti-5Al-5V-5Mo-3Cr. Mater. Des. 2015, 66, 596-610. [CrossRef]

21. Li, H.M.; Li, M.Q.; Luo, J.; Wang, K. Microstructure and mechanical properties of heat-treated Ti-5Al-2Sn-2Zr-4Mo-4Cr. Trans. Nonferr. Met. Soc. Chin. 2015, 25, 2893-2900. [CrossRef]

22. Zhou, M.; Lin, Y.C.; Deng, J.; Jiang, Y. Hot tensile deformation behaviors and constitutive model of an Al-Zn-Mg-Cu alloy. Mater. Des. 2014, 59, 141-150. [CrossRef]

23. Liu, Z.G.; Li, P.J.; Xiong, L.G.; Liu, T.Y.; He, L.J. High-temperature tensile deformation behavior and microstructure evolution of Ti55 titanium alloy. Mater. Sci. Eng. A 2017, 680, 259-269. [CrossRef]

24. Ning, Y.Q.; Yao, Z.K.; Li, H.; Guo, H.Z.; Tao, Y.; Zhang, Y.W. High temperature deformation behavior of hot isostatically pressed P/M FGH4096 superalloy. Mater. Sci. Eng. A 2010, 527, 961-966. [CrossRef]

25. Rabeeh, B.M.; Rokhlin, S.I.; Soboyejo, W.O. Microplasticity and fracture in a Ti-15V-3Cr-3Al-3Sn alloy. Scr. Mater. 1996, 35, 1429-1434. [CrossRef]

26. Da Silva Briguente, N.; Oñoro, J.; Briguente, F.P.; Resende, F.A.; Lidovino dos Reis, J.; Reis, D.A.P.; de Oliveira, A.C. The Influence of Laser Nitriding on Creep Behavior of Ti-4Al-4V Alloy with Widmanstätten Microstructure. Metals 2019, 9, 236. [CrossRef]

27. Sun, J.Z.; Li, M.Q.; Li, H. Deformation behavior of TC17 titanium alloy with basketweave microstructure during isothermal compression. J. Alloys Compd. 2018, 730, 533-543. [CrossRef]

28. Li, H.; Zhao, Z.; Ning, Y.; Guo, H.; Yao, Z. Characterization of Microstructural Evolution for a Near- $\alpha$ Titanium Alloy with Different Initial Lamellar Microstructures. Metals 2018, 8, 1045. [CrossRef]

29. Majorell, A.; Srivatsa, S.; Picu, R.C. Mechanical behavior of Ti-6Al-4V at high and moderate temperatures-Part I: Experimental results. Mater. Sci. Eng. A 2002, 326, 297-305. [CrossRef]

30. Lee, S.B.; Lee, C.S.; Kim, J.S.; Chang, Y.W. Mechanical and microstructural analysis on the superplastic deformation behavior of Ti-6Al-4V Alloy. Int. J. Mech. Sci. 2000, 42, 1555-1569. [CrossRef]

31. Mosleh, A.; Mikhaylovskaya, A.; Kotov, A.; AbuShanab, W.; Moustafa, E.; Portnoy, V. Experimental Investigation of the Effect of Temperature and Strain Rate on the Superplastic Deformation Behavior of Ti-Based Alloys in the $(\alpha+\beta)$ Temperature Field. Metals 2018, 8, 819. [CrossRef]

(C) 2019 by the authors. Licensee MDPI, Basel, Switzerland. This article is an open access article distributed under the terms and conditions of the Creative Commons Attribution (CC BY) license (http://creativecommons.org/licenses/by/4.0/). 